\title{
Rethinking on ethics and regulations in cell therapy as part of neurorestoratology
}

\author{
This article was published in the following Dove Press journal: \\ Journal of Neurorestoratology \\ II January 2016 \\ Number of times this article has been viewed
}

\author{
Alok Sharma ${ }^{1,2}$ \\ Ziad M Al Zoubi ${ }^{3}$ \\ 'Department of Neurosurgery, \\ Lokmanya Tilak Municipal General \\ (LTMG) Hospital and LTM Medical \\ College, Mumbai, India; ${ }^{2}$ NeuroGen \\ Brain and Spine Institute, Mumbai, \\ India; ${ }^{3}$ Jordan Orthopedic and Spinal \\ Centre, Amman, Jordan
}

\begin{abstract}
Ethics, regulations, and evidence-based practices form the foundation of modern medicine. However, in recent years, and particularly in reference to cellular therapy, they have become obstacles to the growth and development of this new form of treatment. Based on four important documents, it is proposed that regulatory bodies and medical associations recommend an alternate way of looking at regulations for cell therapy, so as to ensure that only safe and effective treatments are offered to patients, and that greater availability of these new treatment options is also encouraged. The four documents on which these recommendations are based are: 1) World Medical Association Declaration of Helsinki - Ethical Principles for Medical Research Involving Human Subjects; 2) The International Society for Cellular Therapy "White paper" published in 2010; 3) The Beijing Declaration of the International Association of Neurorestoratology; and 4) New legislation passed in Japan in 2014 on regenerative medicine. These recommendations are: greater permissiveness for the use of cell therapy in incurable conditions, identify legitimate cell therapy services, promote medical innovation, respect the rights of patients to choose treatments, recognize the valid compassionate use of unapproved therapies, recognize the significance of small functional gains, give importance to practice-based evidence and existing published literature, have differing regulations for the different types of cell therapies, and adapt the new Japanese legislation for regenerative medicine.
\end{abstract}

Keywords: cellular therapy, stem cells, ethics, regulations, evidence-based medicine, practicebased evidence, Japan regulations, Korea regulations

\section{Introduction}

Ethics, regulations, and evidence-based practices form the foundation of modern medicine; they have resulted in the standardization of current medical practices and have ensured that only safe and effective treatments are offered to patients. The present regulatory systems that are in place in different countries are primarily structured around the introduction of new drugs and implants. The primary intention of these is to safeguard the patients who are the consumers of medical services from any risk. The evolution of cellular therapy as a new form of treatment in neurorestoratology and other specialties has opened up a new debate on the appropriateness of the current regulatory systems in monitoring and ascertaining cellular therapy as a standard of care.

Cell therapy is defined as "the administration of live whole cells or maturation of a specific cell population in a patient for the treatment of a disease" by the American Society of Gene and Cell Therapy. ${ }^{1}$ Cellular therapy aims to repair the damaged tissue via replacement or regeneration of new cells. The diseases that are suitable for cellular therapy as a part of neurorestoratology are spinal cord injury (SCI), stroke,
NeuroGen Brain \& Spine Institute StemAsia Hospital \& Research Centre Sector 40, Plot No 19, Opposite Rai Vihar, Near Seawood Station, Palm Beach Road, Seawood (W), New Mumbai 400706, India

Email alok276@gmail.com submit your manuscript | www.dovepress.con

Dovepress

http://dx.doi.org//0.2147/JN.S74135 (c) (i) (5) (c) 2016 Sharma and Al Toubi This work is published by Dove Medical Press limited and licensed under Creative Commons Atrribution - Non Commerial (unported License. The full terms of the License are available at http://creativecommons.org/licenses/by-n/3.0/. Non-commercial uses of the work are permitted without any further Dove Medical Press Limited, provided the work is properly attributed. Permissions beyond the scope of the License are administered by Dove Medical Press Limited. Information on how to request permission may be found at: http://www.dovepress.com/permissions.php 
cerebral palsy, autism, muscular dystrophy, motor neuron disease, cerebellar ataxia, spinocerebellar ataxia, multiple sclerosis, traumatic brain injury, dementia, Alzheimer's disease, and Parkinson's disease. For the last three decades, cellular therapy has been an approved clinical treatment for hematological conditions like certain leukemias, lymphomas, myelomas, and anemias. The cells that are transplanted most commonly are hematopoietic stem cells. Many other types of stem cells are being researched for their therapeutic potential.

The ban introduced by American President George Bush on the federal funding of embryonic stem cell research has clouded and biased the discussion of the entire field. ${ }^{2}$ There are also areas that lack clarity, such as whether cell therapy should be considered as a drug or a transplant procedure. There are two extreme views in connection with this treatment option. There are those that strongly oppose the offering of cellular therapy as a treatment form until there is definitive evidence of its effectiveness. On the other hand, there are the practitioners of these treatments who believe that patients suffering from many of the untreatable conditions should not be denied these treatments just because they are still unproven. Both sides are correct in their own ways, and both of these views are like two sides of a coin. The existence of one does not negate the other. Together, they make a whole. It is therefore time to reexamine the ethics, regulations, and principles of evidence-based medicine (EBM) in a new light in connection with cellular therapy.

\section{Ethics and regulations in medical practice}

Ethics comes from the Greek word "Ethos", meaning character. In the modern world, ethics is a wide branch of philosophy that explores the rights and wrongs and morality of one's conduct. It is a process of synthesizing, defending, and recommending right from wrong. ${ }^{3}$ The application of ethical principles in biological sciences, in research, as well as in clinical application is covered under bioethics. The basic principles in bioethics are autonomy, nonmaleficence, beneficence, and justice. The first principle of autonomy implies that the patient should be considered capable of acting intentionally, based on an understanding of the treatment offered, as well as the risks one may assume with such treatment, without an external influence preventing a free and voluntary action. The second principle of nonmaleficence suggests that there should be no harm caused to the patient by providing or denying a treatment. The third principle of beneficence is self-explanatory and suggests that the physician has a duty to benefit the patients, and also to prevent them from any harm that may be caused by a medical treatment. The fourth and final basic principle is the principle of justice, which means that a physician should be fair in offering his or her services, and that there should not be any preferential attribution of services. ${ }^{3}$ Although these principles have been known and socially accepted for centuries, these have been violated intentionally, as well as unintentionally, in the past. Incidences like the medical experiments conducted on the prisoners of war in Germany ${ }^{4}$ were intentional examples, and the occurrence of phocomelic infants after thalidomide consumption was an unintentional example of this violation. ${ }^{5}$ These violations gave rise to the need of regulating medical practices to ensure strict observance of the ethical principles in medical practice, as well as in research. In the modern world, ethical principles are implemented through various regulatory bodies to protect the patients from being taken advantage of and to protect them from any harm caused by the treatment or by medical incompetence. The guidelines formed by these regulatory bodies are based on EBM.

\section{Principles of evidence-based medicine}

EBM is defined as "The conscientious and judicious use of current best evidence from clinical care research in the management of individual patients". ${ }^{6}$ EBM was conceptualized when medical information started growing exponentially and the effectiveness of routine medical practices was being questioned. EBM follows rigorous steps to come to a most informed conclusion about the effectiveness of an intervention based on the available medical information. ${ }^{6}$ It follows several steps like forming a relevant clinical question; searching for the evidence to answer that question; appraising the evidence; integrating that evidence into the clinical practice, while keeping in mind patient preferences; evaluating the outcome of such integration using standardized scientific tools; and then documenting and disseminating these findings for others to appraise. ${ }^{7}$ Evidence in EBM can come from collective medical experience, expert opinion, observational case reports or case series, and experimental testing in the form of cohort studies or controlled studies, but there is a hierarchy. Collective medical experience and expert opinions are considered to have the least amount of applicability, while randomized controlled trials (RCTs) and systematic reviews of such trials are the most applicable evidence. The quality of the evidence is based mainly on epidemiological principles. ${ }^{8}$ The main purpose of EBM is to empower clinicians with the most up-to-date medical 
knowledge and to facilitate informed clinical decisions based on the evidence of effectiveness. This has prevented the consumption of unsafe drugs, serious adverse effects, and the use of ineffective medical practices. However, most of the revolutionary concepts of modern medicine were developed in the late 19th and early and mid-20th centuries, when the notion of EBM did not exist. This period has witnessed some of the most extraordinary medical inventions and they happened in the absence of regulatory bodies.

EBM has been the most popular method of appraising evidence thus far due to a methodical and scientific approach. However, the approach of EBM also has its limitations. EBM has been criticized for the difficulty in applicability for an individual patient. ${ }^{8}$ The elaborate process of coming to an informed conclusion may sometimes be impossible in real clinical scenarios. Further, EBM relies heavily on empirical evidence for use in clinical practice; but what does one do in the absence of such evidence? The most significant fallacy of EBM is that the lack of evidence for efficacy is considered synonymous with a lack of efficacy itself. ${ }^{8}$ The empiricism of EBM undermines the philosophical origin of the medical innovations that are based on clinical expertise and the pathophysiological knowledge of the disease. ${ }^{8}$ The process of finding and developing a new medical treatment through modern EBM is a long and expensive process. This includes preclinical laboratory and animal testing, as well as multiple phases of human testing to establish the treatment's safety and efficacy, first in a small group and then in larger groups. ${ }^{9}$ The average time taken for this process is $6-8$ years, and the average money spent is over US $\$ 5,000,000,000 .{ }^{10}$ A single clinical practitioner cannot afford the time or the cost required in this process.

The evolution of the field of medicine is thus now dependent upon the corporate giants, who can spend the time and money to test newer medical treatments, rather than the experts in the field. It is also now driven by consumer demand for such medicines rather than by medical curiosity and the need to cure a disease. The profitability of developing a medicine for rare diseases is questionable and, therefore, the focus of corporate organizations is on more common diseases that have a larger market. So the questions that need to be debated are: 1) although evolved to help patients, are the current evidence-based regulations observing the basic bioethical principle of justice?; 2) in the early 20th century, medicine evolved through the knowledge and experience of experts in medicine, but it is now stunted due to the enormous costs of the approval processes - are we then really observing the principle of beneficence?; and 3) is the system of EBM, which was developed to make efficient scientific and evidence-based clinical decisions, now perhaps slowing the pace of medical evolution? Therefore, although very essential, the practice of EBM needs to be reexamined, especially with reference to cell therapy.

\section{Ethical dilemmas of cellular therapy}

The last decade has seen the evolution of cellular therapy. This is the field of regenerative medicine where healthy tissues could be used to replace or repair damaged tissues. Cell therapy holds a special place in the development of neurorestorative treatments for otherwise incurable neurological conditions. The development of cellular therapy has also sprouted debates on various ethical grounds based on religious, social, political, and capitalistic beliefs. It has been unanimously accepted that the science of regenerative medicine is vast and holds tremendous potential for finding the cure to various untreatable diseases. But in the past, there has been strong opposition to research associated with embryonic stem cell therapy. The genesis of this was the ban put forth by President George W Bush on the federal funding of embryonic stem cell lines developed after $2001 .^{2}$ This ban still remains in public memory with the result that subsequent clinical developments in the field have not received the recognition that they should have. In any case, this ban was subsequently lifted by President Barak Obama. ${ }^{2}$ Cellular therapy consists of various other types of cells that are not of embryonic origin. The ethical dilemmas associated with embryonic stem cells need not be applied to the cells of nonembryonic origin, like umbilical cord stromal cells and adult stromal cells. The medical community, patients, and regulatory authorities need to make this distinction, and the objections for the use of one type of cell should not be applied to the other types.

Another facet of the ethical considerations is using cellular therapy as a form of treatment. Clinical practitioners in the field of cellular therapy face a moral and an ethical dilemma every single day, such as whether it is ethical to offer a treatment that has not yet been approved as a standard of care for that disease. However, if these practitioners deny safe and available treatment to patients who have incurable diseases just because their efficacy has not been established by modern medical standards, and they wait for it to be established while the patients wither away, is that ethical? The basis of this dilemma lies in the conflict of the two fundamental principles of bioethics: beneficence and nonmaleficence. On the one hand, one is expected to always benefit the patient; on the other, one may not offer the treatments 
to the patients unless those treatments are approved as per modern medical standards. By not offering such treatments, one is actually violating the principle of nonmaleficence through omission. EBM in modern medicine has become synonymous with ethical medical practice, but the unique challenges put forth by the evolution of cellular therapies demands us to rethink this. Cellular therapies are far more dynamic and diverse than drug therapies, and therefore it may take decades or longer to generate empirical evidence validating the use of cellular therapy as a treatment form. The generation of such evidence will also be dependent upon various sociopoliticoeconomic variables, and not on the need for medical innovation alone.

Is it fair then, that on one hand, we claim to protect patients from adverse effects and the ineffectiveness of therapy using EBM, whereas on the other hand, we let the patients die or suffer waiting for the treatment? It is time to revisit the concept of "practice based evidence" (PBE) and not rely solely on "evidence based medicine". While EBM may perhaps jeopardize the autonomy of the patients in choosing an unproven treatment for the lack of any other proven treatment, PBE protects such autonomy. $\mathrm{PBE}$ respects the evidence generated from a single practitioner, whereas EBM will disregard it as the lowest form of evidence. However, this lowest form of evidence is what has given medicine its most brilliant inventions. The medical field progressed when the individual clinical practitioners pioneered newer forms of therapy based on their clinical experience and expertise. Day-to-day decisions made in intensive care setups and operating rooms are primarily influenced by the clinical circumstances at hand, as well as by the clinicians' own experiences in dealing with such situations. Not everything in medicine can be measured with the yardstick of EBM; neither can it all be tested using EBM. Further, the following questions remain: when can a particular form of treatment be considered to have conclusive evidence? How many clinical trials will it take for us to get that evidence? The more daunting question is whether we have the funds, the resources, and the time to conduct a multitude of trials. Should we accept the slowing of the pace of medical advancements for the lack of funds and resources for formal clinical trials? PBE could thus be a key to faster progress in medicine. Both the paradigms of EBM and PBE need to coexist. The science of cellular therapies provides a unique opportunity for this coexistence. This does not mean that the treatments should not be tested scientifically. Novel treatments must be very stringently monitored for their safety. However, once their safety has been established, the use of such treatments may be permitted in cases of the diseases where there are no other treatments available. Not only should these treatments be permitted, but more and more practitioners should be involved in providing these treatments so that a large body of evidence can be generated. Greater availability would also make such treatments easily available and less expensive. Rather than relying on corporate organizations to generate evidence, individual practitioners and institutions should also be empowered and entrusted with this task.

One ethical dilemma that often confronts practitioners of cellular therapy is whether it is appropriate to charge for treatments that are yet unproven. The answers to a question like this are complex; however, in general, it could be said that what is important is whether a treatment method should or should not be offered to a patient. If it is ethical to offer a treatment to a patient that will benefit that patient, then there should not be any ethical issues about charging for that treatment.

\section{Clinical progress in the field of cellular therapy in neurorestoratolgy}

The last decade has seen tremendous clinical progress in the field of cellular therapy, which is in the field of neurorestoratology. Much of this is published in peerreviewed journals, and a review of all this work clearly establishes the safety and efficacy of cellular therapy. Irrespective of the types of cells used, or the method used to transplant them, published work from all over the world has shown that this is a safe treatment method, and it helps to improve the quality of life of patients via the neurological improvements that it produces. It is important that regulatory bodies and medical associations all over the world take cognizance of this published data while forming regulations for cell therapy. This PBE should now be the basis for evolving standards of care until multicenter prospective randomized clinical trials give us more definitive data.

\section{Review of the published literature highlighting the safety and efficacy of cellular therapy in neurorestoratology Spinal cord injury}

A review of published work in cellular therapy clearly establishes the safety and efficacy of this treatment. In the case of SCI, there have been over 66 published papers in which 1,599 patients have been treated using various types of cellular therapies, and among these, 844 patients have shown 
functional and neurological improvements and with no major adverse events reported. Some of the significant findings come from: 1) Huang et al who conducted a study on 108 complete chronic SCI patients who were administered with olfactory ensheathing cells. On a long-term follow up after $3.47 \pm 1.12$ years, there was no deterioration, but improvement in neurological function was recorded. ${ }^{11}$ 2) Saberi et al carried out Schwann cell transplantation in four patients with SCI. On follow up 1 year later, no adverse events were noted and the transplantation was found to be safe and feasible. ${ }^{12}$ 3) Moviglia et al carried out transplantation of bone marrow mononuclear cells in eight SCI patients and reported the treatment to be safe and effective. ${ }^{13} 4$ ) Sharma et al conducted a clinical study including 56 patients with chronic cervical SCI. The patients were intrathecally administered adult autologous bone marrow mononuclear cells (BMMNCs) and were followed up for 2 years \pm 1 month. Functional improvement was noted in various symptoms and on the Functional Independence Measure scale, which was statistically significant. ${ }^{14}$ 5) Sharma et al conducted another clinical study on the effects of intrathecal transplantation of BMMNCs in thoracolumbar SCI. A total of 110 patients were followed up for 2 years \pm 1 month. Ninety-one percent of the patients showed recovery in various symptoms like spasticity, sensory deficits, motor deficits, poor balance, and bladder/bowel incontinence, as well as the loss of sensations. Patients also achieved greater functional independence. ${ }^{15}$ 6) Tabakow et al assessed the safety and feasibility of transplantation of autologous mucosal olfactory ensheathing cells and olfactory nerve fibroblasts in three patients with complete SCI with a 1-year follow up. The researchers observed no deterioration, adverse events, neuropathic pain, infection, or tumerogenesis, but neurological improvement was only observed in the transplanted group. ${ }^{16}$

\section{Cerebrovascular accident}

In one of the common neurological disorders, like cerebrovascular accidents, cellular therapy has shown great promise. There are more than eleven published studies including more than 334 patients. Some of the important studies are as follows: 1) A study conducted by Sharma et al demonstrated that out of 27 patients, $51.85 \%$ of patients showed significant improvements, $29.62 \%$ of patients showed moderate improvement, mild improvements were observed in $11.11 \%$ of patients, whereas $3.7 \%$ of patients showed no improvements in any of the symptoms. ${ }^{17}$ 2) Li et al in 2013 conducted a study where they assessed the clinical effect of bone marrow mononuclear cells, including mesenchymal stromal cells, in patients with intracerebral hemorrhage. One hundred patients were divided into a study (number [n] $=60)$ or a control group $(n=40)$. Neurological and functional improvements were observed in $86.7 \%$ of patients in the intervention group, as compared to $42.5 \%$ of patients in the control group. ${ }^{18}$

\section{Dementia and Alzheimer's disease}

Dementia is defined as a chronic or persistent disorder of the mental processes caused by brain disease or injury and marked by memory disorders, personality changes, and impaired reasoning. ${ }^{19}$ Alzheimer's disease and vascular dementia (VaD) are two forms of this condition. While there are presently no published clinical studies on Alzheimer's disease, there are animal studies that suggest the efficacy of cellular therapy in Alzheimer's. ${ }^{20,21}$ These studies have provided evidence about the survival, migration, and differentiation of stem cells into different types of neural cells. The transplanted cells were also seen to have differentiated into cholinergic neurons and parenchymal tissue. In addition, differentiation cells were also observed to secrete various growth factors, neurotrophic factors, and to enhance neural plasticity. ${ }^{22}$ In VaD, Sharma el al reported clinical and radiological improvement after cell therapy. ${ }^{23}$ Larger clinical studies are needed to establish the role of cell therapy in Alzheimer's disease and VaD.

\section{Amyotrophic lateral sclerosis}

Amyotrophic lateral sclerosis (ALS) is of a particular interest in neurorestoratology given the progressive and incurable nature of the disease. There have been ten studies thus far evaluating the effects of cellular therapy in 203 patients. ${ }^{24-32}$ These studies have demonstrated beneficial effects on survival, motor function, and in stabilizing the progressive deterioration in the forced vital capacity of ALS patients. Some of the notable results are found in the following studies: 1) Prabhakar et al conducted a pilot study of ten patients receiving adult autologous BMMNCs intrathecal transplantation. The serial measurements of the revised ALS Functional Rating Scale (ALS-FRSr) showed that there was a slowing of the drop in the ALS-FRSr scores as compared to earlier epidemiological findings, suggesting an alteration in the disease progression. ${ }^{32}$ 2) Sharma et al presented a clinical analysis comparing the survival of 37 patients who received intrathecal transplantation of adult autologous bone marrow mononuclear cells with controls who did not receive cellular transplantation; they had observed increased survival in the treatment group. There were improvements observed clinically in bulbar symptoms and in gross and fine motor 
functions. ${ }^{33}$ Huang et al and Chen et $\mathrm{al}^{34-36}$ published three reports. 1) In a controlled pilot study involving 35 patients with probable or definite ALS, determined by the assessment of ALS-FRSr, the functional deterioration was significantly slower in the OEC-treated group than in the control group during the last 2 months $(P<0.05)$. 2) A total of 327 patients with probable or definite ALS received OEC transplantation with 77.1\% (252/327) neurological functional improvement. 3) Patients with multiple cell transplants and long-term observation definitely can demonstrate neurological functional and breathing ability recovery.

\section{Autism}

The research in the use of cellular therapy for autism has been promising. The beneficial results in this otherwise untreatable condition affecting one in every 160 children are significant and life altering. The following published works highlight this: 1) Sharma et $\mathrm{al}^{30}$ reported on 32 children diagnosed with autism on the basis of the Diagnostic and Statistical Manual of Mental Disorders, 4th edition, text revision (DSM-IV-TR) criteria. These children underwent a regime of intrathecal autologous BMMNCs transplantation and multidisciplinary rehabilitation. Statistically significant improvements were noted on outcome measures like the Clinical Global Impact scale and the Indian Scale for Assessment of Autism, which grade the severity of the disease, and a clinically significant change was also found in functional independence, as measured on the Functional Independence Measure scale. ${ }^{37}$ 2) Lv et $\mathrm{al}^{38}$ reported on their controlled clinical study that examined and compared the effects of cellular transplantation with controls. There were three groups: patients who received human cord blood mononuclear cells alone; those who received cord blood mononuclear cells in combination with umbilical cordderived mesenchymal stem cells; and the control group that received neither. Cells were transplanted intrathecally and intravenously. A total of 37 patients were divided into these three groups, and outcomes were measured with the Clinical Global Impact scale, the Childhood Autism Rating Scale, and the Chinese version of the Aberrant Behavior Checklist. Both groups who received transplantation showed statistically significant improvements as compared to the controls; however, the group that received a combination of therapies showed greater improvement.

\section{Cerebral palsy}

Various clinicians have published their findings in the use of cellular therapies in cerebral palsy. There are over
19 published studies including 344 patients. Some of the salient studies are as follows: 1) Chen et al conducted a randomized controlled clinical trial on 33 patients with cerebral palsy who were administered with olfactory ensheathing cells. The authors reported functional improvement in these patients. ${ }^{39}$ 2) Chernykh et al conducted a study on 16 children with cerebral palsy using M2-like macrophage cells. These cells were found to improve the neurological status of the patients and were safe. ${ }^{40} 3$ ) Sharma el al conducted an open label non randomized study to find out effects of autologous BMMNCs intrathecal transplantation in 40 children suffering from cerebral palsy. Out of these 40 children $95 \%$ of the children showed improvement at 6 months. Six children underwent pre- and post- intervention Positron Emission Tomography-Computed Tomography scanning of the brain, which suggested improvement in the brain metabolism and function. ${ }^{41}$ These published clinical results are only some examples of a much larger group of work that clearly establish the importance of cellular therapy as an overall part of neurorestorative treatments.

In spite of this clinical progress and the increasing number of publications demonstrating the benefits of cellular therapy for incurable neurological diseases, the regulations and guidelines in most countries are not conducive to promoting clinical implementation. Cellular therapy is an extremely dynamic field and it should be regulated, but the regulatory bodies should take into consideration the fundamental differences between cellular therapy and drug therapy. The regulatory bodies need to take all of the published work noted earlier into account before forming new regulations for cell therapy.

\section{Role of regulatory bodies governing research and treatments using cellular therapies}

Although individual medical expertise and experiences are of importance and should be regarded as evidence, caution needs to be exercised so as to cause no harm. Regulatory bodies therefore have a great role to play. Regularizing and monitoring medical practices is very important to protect patients from harm; however, regulations should not restrict or slow down the development of newer medical treatments. We are therefore proposing an alternate way of looking at regulations for cellular therapy based on the established and published principles and methods. The following actionable recommendations are based on four important documents: 1) the World Medical Association (WMA) Declaration of Helsinki - Ethical Principles for Medical Research Involving Human Subjects; 2) the International Society for 
Cellular Therapy (ICST) "White paper" published in 2010 in Cytotherapy; 3) the Beijing Declaration of the International Association of Neurorestoratology (IANR); and 4) new legislation passed in Japan in 2014 that revised the existing Pharmaceutical Affairs Law to define new medical products that contain stem cells, which were termed regenerative medicine products, and that offered fast-track approval for stem cell therapies.

\section{Actionable recommendations Acceptance of unproven cellular therapies for the treatment of incurable conditions (based on the World Medical Association's Declaration of Helsinki)}

Use of cellular therapies that are found to be safe should be permissible and ethical as a form of treatment for incurable disorders on the basis of the WMA Declaration of Helsinki: Ethical Principles for Medical Research Involving Human Subjects ${ }^{42}$ which, in its clause 37, states that:

In the treatment of an individual patient, where proven interventions do not exist or other known interventions have been ineffective, the physician, after seeking expert advice, with informed consent from the patient or a legally authorized representative, may use an unproven intervention if in the physician's judgment it offers hope of saving life, re-establishing health or alleviating suffering. This intervention should subsequently be made the object of research, designed to evaluate its safety and efficacy. In all cases, new information must be recorded and, where appropriate, made publicly available.

What this states is that it is ethical for a physician to treat a patient with an unproven therapy if no other treatment options are available. All guidelines and regulations regarding cell therapy should consider this important part of the Helsinki Declaration. Therefore, there should be a distinction between diseases for which there are regularly accepted treatments and those for which there are not, and the guidelines and regulations should be more permissive for conditions that currently have no or unsatisfactory treatment options. Work being done by centers following this aspect of the Helsinki Declaration should be considered ethical and legitimate.

Legislation in various countries recognizes the compassionate use of unproven therapies; European medicines agency, Committee for Medicinal Products for Human Use (CHMP), Evaluation of Medicines for Human Use:
Regulation (EC) no 726/2004 of the European parliament and of the council article 83.2 of the European Union Legal Framework $^{43}$ defines compassionate use as:

A medicinal product available for compassionate reasons to a group of patients with a chronically or seriously debilitating disease or whose disease is considered to be life-threatening, and who cannot be treated satisfactorily by an authorized medicinal product. The medicinal product concerned must either be the subject of an application for a marketing authorization or must be undergoing clinical trials.

\section{Distinction between legitimate cell therapy medical services and fraudulent services (based on the ICST white paper)}

Regulatory bodies need to differentiate between legitimate cell therapy medical services and fraudulent services.

The ICST "white paper" published in 2010 in Cytotherapy ${ }^{44}$ gives clear guidelines for assessing the legitimacy and scientific rigor of the centers conducting stem cell research and offering stem cell therapy. There are three points highlighted in this paper for the consumers that serve to be a distinction between legitimate and fraudulent centers.

1. The center providing the therapy must have scientific publications, presentations and recognition in their field of practice.

2. There should be an established safety record of the center and if any adverse events are noted they should be published in the peer reviewed journals.

3. The therapies should be offered only after an informed consent which provides information on risks, benefits, cost of the therapy, other therapy options available, safety of the therapy, compensation provided by the investigator in case of any adverse event and any conflict of interest of the investigator.

Therefore centers, whose work is peer reviewed, transparent, published in peer reviewed publications, presented in professional society presentations and has received scientific recognition; centers that have a good safety and regulatory history and the centers that have obtained informed consent may be considered as centers offering legitimate cell therapy.

\section{Distinction between clinical trials and medical innovation (based on the ICST white paper)}

The regulatory bodies should make a clear distinction between clinical trials and medical innovation. This distinction can 
be made on the basis of the recommendations of the ICST white paper. ${ }^{44}$

The white paper characterizes cellular therapy as medical innovation if it is provided by a qualified health care professional in their field of practice. Under circumstances when patients are not eligible for the controlled trials but are seeking the therapy, the researchers can offer the unproven therapy as a treatment option only after truthfully and ethically informing the patient about the nature of these therapies. The white paper emphasizes on the possibility for co-existence of both the paradigms of medical research and medical innovation.

Based on this, it can be stated that unapproved cell therapy should be considered as an ethical and legitimate part of medical innovation, so long as it is performed by qualified health care professionals in their practice of medicine; the researchers are competent, and those seeking treatment are truthfully and ethically informed. There is a role for both clinical trials and medical innovation in the cell therapy global community.

\section{The basic right of a patient to seek treatment should be respected (based on the ICST white paper)}

Current medical regulations may be viewed as violating the basic bioethical principle of the autonomy of the patients with reference to cellular therapy. Implementing evidence-based guidelines alone implies that the patients' rights to choose a treatment that is safe are being denied. The ICST white paper $^{44}$ is in agreement with this and states that the patients may seek cellular therapies, which is their right and unless there is a high probability of causing harm to the patient such a treatment should not be withheld by the institution. However, the patients also have a right to information and accurate information about the safety, side effects and effectiveness of the treatment must be provided to the patients, prior to the therapy. Therefore when providing an innovative therapy, patients' right to informed consent must be respected and the therapy should not be provided without obtaining an informed consent from the patient.

Based on this, it can be stated that the right to seek treatment is the fundamental right of the patients and their families, and that this should not be taken away by any regulatory or professional body. In addition, the patients have a right to information and a right to informed consent, which the treating physicians have to make available to the patients and their families.

\section{Distinguishing various centers offering cellular therapy (based on the recommendation of the ICST white paper)}

Various centers offering cellular therapy should be distinguished, as given in the ICST white paper, ${ }^{44}$ which states that the ICST guidelines should clearly divide and differentiate between:

1. Approved/standard therapies (eg, hematopoietic stem cell transplant and other cellular therapies approved for marketing)

2. Controlled clinical trials

3. Valid compassionate use of unapproved therapies

4. Treatments not subject to independent scientific and ethical review.

At present, most regulatory bodies only recognize: 1) approved/standard therapies (eg, hematopoietic stem cell transplant and other cellular therapies approved for marketing); and 2) controlled clinical trials. Anything apart from this is not recognized as ethical or legal. We believe that 3 ) the valid compassionate use of unapproved therapies needs to be recognized as a separate, ethically accepted, and legitimate alternative.

\section{Recognition of the importance of cellular therapy as part of neurorestorative therapies (based on the Beijing Declaration of the IANR)}

The IANR, through its Beijing Declaration, ${ }^{45}$ highlights the importance of cellular therapies and recognizes the importance of small functional gains that can have a significant effect on the quality of life of patients. Clauses 2, 5, and 7 of the Beijing Declaration state:

2. Worldwide neurological impairment due to neurodegeneration and neural injury is a major factor reducing human longevity and quality of life. Neurorestoratology seeks therapeutic solutions to this problem.

5. Neurorestorative therapies include regeneration and reconstruction of nervous tissues by transplantation of tissue, cells, or biomaterials and bioengineering, modulation by electromagnetic stimulation, pharmaceutical or chemical therapies, and combinations of the above.

7. Neurorestoratology recognizes the importance of small functional gains that have significant effects on quality of life. Neurorestoratology is interested in the mechanisms of spontaneous activity and enhancing this recovery. 
Regulations need to keep in mind the facts that small functional gains can have a significant effect of the quality of life of patients suffering from serious neurological disorders, and that cellular therapy is an important component of neurorestoratology that needs to be encouraged and made more widely available.

\section{Giving importance to practice-based evidence}

While there is no questioning the important role of the principles of EBM in the practice of modern medicine, there is now an emerging alternate view that maybe the stringent and demanding conditions of EBM are slowing down medical innovation. ${ }^{8,46-49}$ This is particularly relevant in the case of cellular therapy. In such a scenario, it is important to give importance to PBE.

Conventional EBM only recognizes class 1 evidence in the form multicentric RCTs as an acceptable standard for accepting any new treatment form as a standard of care. There are several reasons why RCTs may not necessarily be the only accepted evidence for cellular therapy.

1. It may take several years in the field of cellular therapy to complete multicentric RCTs for all the different cell types.

2. Such clinical trials are very expensive to do, and so they can be done only by large corporate organizations; this therefore excludes individual practicing physicians from being able to generate this type of clinical evidence.

3. The concept of RCTs primarily originated to evaluate new drugs for their safety and efficacy. The only variable that evaluates a new molecule is the dose of the drug. In cellular therapy, however, there are multiple factors at play. There are different types of cell therapies and there are many variables, such as the number of cells, the methods of transplantation, etc. This means that even if an RCT is performed, then all that the RCT will prove is whether that particular type of cell, in that particular cell count, given in that particular way is effective or not. It will not mean that a different cell type given in a different cell dose or transplanted in a different manner will have the same results.

In view of this, $\mathrm{PBE}$ in the form of published papers showing safety and efficacy should also be accepted as clinical evidence instead of depending on RCTs alone.

It is important to note that while no patients have been reported or known to have died due to cell therapy, there are thousands of patients dying whose lives could have been saved, had they had the opportunity to receive cell therapy. This is particularly true for patients suffering from ALS, Duchenne muscular dystrophy, and so on. In other words, patients are dying of diseases for which treatments are available but not accessible to patients due to regulatory constraints. Therefore, it is important that the regulatory authorities look at regulations for cellular therapy from the perspective of patients suffering from otherwise untreatable and life-threatening conditions.

A major controversial issue in this field is what should be the basis of accepting cell therapy as an approved mode of therapy for newer indications. In the field of Neurorestoratology these include spinal cord injury, cerebrovascular accidents, dementia and alzheimer's, ALS, autism, cerebral palsy etc. Waiting for class 1 evidence in the form of prospective randomized controlled clinical trials will take several years. Till then hundreds of thousands of patients may be deprived of a treatment that is available but which they cannot receive because of regulatory considerations. At the same time there cannot be a blanket sanction to use cellular therapy for new indications. A middle ground by which patient safety is ensured and patients are not deprived of available treatments would be to accept published literature (case series, clinical studies, case reports) showing proven safety and presumed efficacy in peer reviewed journals as a basis for accepting new indications for the use of cellular therapy.

\section{Regulations need to make a distinction between different types of cellular therapies}

Unlike drug therapy, cellular therapy consists of very different types of cells and it is important that regulations make a distinction between these different types of cells. Having common regulations for all cellular therapies would be like having common regulations for alcohol, sodas, and homemade orange juice, covering them all under the category of beverages.

It is important that the following distinctions are made:

1. allogenic or autologous;

2. source of the cells (eg, embryonic, umbilical cord, adult stromal cells, induced pluripotent stem cells, olfactory ensheathing gial cells, etc; and

3. significantly manipulated or minimally manipulated.

So, broadly speaking, cells that are autologous, of adult origin, and minimally manipulated should have more permissive regulations than the cells that are allogenic, of embryonic origin, or significantly manipulated. 
Regulations in some countries such as the USA and Korea recognize this and make specific mention of excluding such cell therapy from the regulations.

The USA, Department of Health and Human Services, Code of Federal Regulations, Food and Drug Administration, Part 1271: Regulations for Human cells, Tissues, and Cellular and Tissue based products: ${ }^{50}$ The US Food and Drug Administration makes a clear distinction of minimally manipulated cells and autologous transplantation from other cell types when it states in its article 1271 15B (Human cells, Tissues, and Cellular and Tissue based products), that 'You are not required to comply with the requirements of this part if you are an establishment that removes human cells, tissues and cellular and tissue-based products from an individual and implants such products into the same individual during the same surgical procedure'. What this implies is that minimally manipulated and autologous cell therapy should not have regulations that are in place for other human cells, tissues, tissue based products and drugs.

Korean Regulation on Review and Authorization of Biological Products: ${ }^{51}$ The Korean regulations on review and authorization of biological products also make this distinction since on page number 3 of the regulations document they have excluded minimally manipulated cells from their definition of cell therapy products. They state that "“cell therapy product" means a medicinal product manufactured through physical, chemical, and/or biological manipulation, such as in vitro culture of autologous, allogeneic, or xenogeneic cells. However, this definition does not apply to the case where a medical doctor performs minimal manipulation which does not cause safety problems of autologous or allogeneic cells in the course of surgical operation or treatment at a medical center (simple separation, washing, freezing, thawing, and other manipulations, while maintaining biological properties).

\section{Adapting regulations from countries that have been progressive and more permissive of cellular therapies}

Japanese regulations for regenerative medicine took a revolutionary turn when a law called, regenerative medicine promotion law, was passed by the Japanese Diet. In accordance with this law an act and a partial amendment in the existing law was implemented to promote stem cell therapy, assure safety of the therapy provided, and facilitate early and safe marketing of the stem cell products and therapies. The key elements of the new Japanese regulations are as follows:
1. The Pharmaceuticals and medical devices agency, partial amendment of Pharmaceuticals Affairs law, renamed as Pharmaceuticals, Medical Devices, and Other Therapeutic Products Act (PMD Act): ${ }^{52}$ A recent partial amendment made by Pharmaceuticals and Medical Devices Agency (PMDA) in the Japanese Pharmaceutical Affairs law in 2013 that was implemented in 2014 has created a separate approval channel for regenerative medicine. Rather than using phased clinical trials, investigators will have to demonstrate efficacy in pilot studies of as few as 10 patients in one study if the change is dramatic enough or a few hundred when the improvement is marginal. ${ }^{53}$ If the efficacy can be surmised the treatment will be approved for marketing. At that stage the treatment could be approved for commercial use as well as national insurance coverage.

In addition to promoting fast track marketing approval to the cell based products and therapies, PMDA and Ministry of Health, Labor, and Welfare (MHLW) also implemented two other acts to promote regenerative medicine.

2. MHLW and PMDA act on safety of regenerative medicine. ${ }^{54}$

As per the act of safety of regenerative medicine the regenerative medicine products and treatments are categorized as regenerative medicine I (High risk), Regenerative medicine II (Medium risk) and Regenerative medicine III (Low risk) (Figure 1). The approval channels and procedure for these classes of medicine are different.

a) Low risk regenerative medicine products (Class III): For low risk regenerative medicine products and treatments an approval is required to be granted from a specialized committee, Certified Committee for Regenerative Medicine. This committee includes experts in the regenerative medicine technologies as well as legal experts which is approved by the MHLW. This committee is from within the medical institute. A provision plan has to be submitted to the MHLW after hearing opinions of the Certified Committee for Regenerative Medicine and then implementation may be done.

b) Medium risk regenerative medicine products (Class II): For medium risk regenerative medicine products additional oversight is added in the form of a Certified Special Committee for Regenerative Medicine, which consists of experts in the field of regenerative medicine with capabilities for special- 


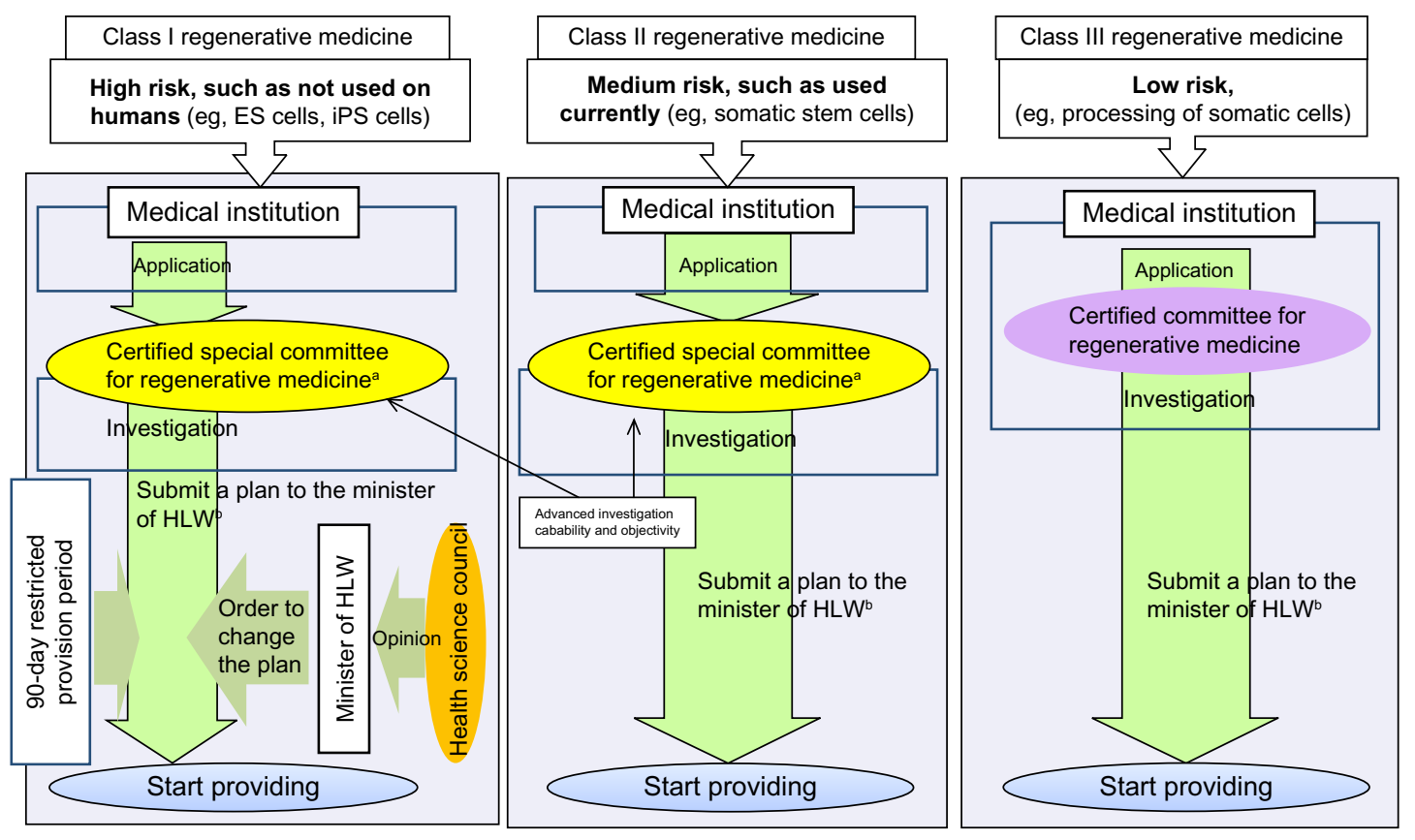

Figure I Categorization of regenerative medicine.

Notes: a Certified Committee for Regenerative Medicine is a council-type committee consisting of knowledgeable persons including experts on the technologies of regenerative medicine or legal matters, which is approved by the Minister of HLW through certain formalities. Certified Special Committee for Regenerative Medicine is the Certified Committee for Regenerative Medicine with specifically advanced investigation capability and objectivity. ${ }^{\mathrm{b}}$ The procedure of submitting a provision plan will be obligated. Penalties will be imposed if regenerative medicine is provided without submitting a provision plan. Data from Ministry of Health and Welfare Japan. ${ }^{54}$

ized investigation and objectivity. This committee is from outside of the institute. A provision plan has to be submitted to the MHLW after hearing opinions of the Certified Special Committee for Regenerative Medicine and then implementation may be done.

c) High risk regenerative medicine products (Class I): For high risk regenerative medicine products, after approval from Certified Special Committee for Regenerative Medicine the MHLW will impose a certain period of restricted implementation during which the MHLW will confirm the safety etc, by hearing opinions of the Health Science Council. The MHLW can order change of the plan if there is nonconformity to the standards of safety.

Thus the Japanese government has lowered the bar for regenerative therapies dramatically by requiring limited safety and efficacy data and offering a fast track clearance method. It has made three classifications of regenerative medicine based on risk, with the low risk category only requiring an institutional committee approval, the medium risk requiring the approval from a committee outside the institute and the high risk having a very stringent regulatory process. Regulatory bodies from other countries should consider following the Japanese model of regulations for regenerative therapies.

Korean Food and Drug Association (KFDA) Regulation on review and authorization of biological products, Article $41:{ }^{51}$ In addition to excluding minimally manipulated cells from the definition of cell therapy product, the KFDA also has a fast track review process for the use of cell therapy in life threatening, serious diseases and conditions for which treatment is not possible with existing therapy. The article 41 states that a fast track review process or allowance of post marketing submission of some of the documents may be permitted for: 1) therapies and medicinal products for diseases like AIDS, cancer and other life threatening or serious illnesses, 2) therapies and medicinal products for diseases that have no existing treatment, and 3 ) therapies and medicinal products that have a preventive or therapeutic effect against pandemic infectious diseases.

The Korean regulations recognize that minimally manipulated cell therapy need not have the same regulations as other cell products and that a fast track clearance should be given for treatment of medical conditions that are serious and have no other treatment options. Other regulatory bodies need to keep these two important points in consideration whilst framing their regulations. 


\section{Two sides of the coin}

Although the recommendations noted herein would make cell therapy more easily available for otherwise incurable medical conditions, concerns have been raised regarding the possible negative impact of these on research and patient care. ${ }^{55}$ The currently followed principles of EBM ensure that only a definitively proven safe and effective treatment becomes the standard of care. It is possible that overenthusiastic researchers and scientists may overestimate the potential of cellular therapy. There have been surgical and medical procedures that evolved as medical innovations later lost their validity when tested with clinical trials. ${ }^{49}$ Balancing of both these aspects of flexible regulations and EBM is a delicate matter. Both these aspects are best described in a quote from President Barack Obama's speech, when he lifted the ban on federal funding for embryonic stem cell research, on March 9, 2009:56

There is no finish line in the work of science. The race is always with us - the urgent work of giving substance to hope and answering those many bedside prayers, of seeking a day when words like "terminal" and "incurable" are finally retired from our vocabulary.

\section{Conclusion}

Cellular therapy is a new paradigm in the practice of medicine, since never before in the history of modern medicine have we had the capability to repair and replace damaged tissue. This is an opportunity of epic proportions, as we have a greater aging population worldwide, which is likely to be affected by many of the degenerative processes that cellular therapy can help with. The possible benefits to humanity as a whole are unprecedented. In no other field of medicine have regulations slowed down the development of a field as in cellular therapy. Therefore the regulators and decision makers from different countries must take into account the following actionable recommendations: 1) Cellular therapy should have a separate faster regulatory pathway in comparison to regulations for drugs, 2) Low risk cell therapy such as autologous and minimally manipulated cell therapy should either be excluded from the regulations or should be permitted with institutional oversight only, 3) Fast track approval should be given for the use of cellular therapy for serious medical conditions and for those that have no other treatment options, and 4) Newer indications for the use of cellular therapy should be considered as acceptable based on existing publications demonstrating proven safety and presumed efficacy in peer reviewed journals.

With the above principles it is possible to have more permissive regulations for cellular therapy so that we shall be able to simultaneously ensure that the patients with serious illnesses get the benefits of cellular therapy whilst an adequate check is kept on the medical practices in this field to ensure patient safety.

\section{Disclosure}

The authors report no conflicts of interest in this work.

\section{Reference}

1. asgct.org [Homepage on the Internet], New York: American society of gene and cell therapy. Available from: http:/www.asgct.org/generalpublic/educational-resources/gene-therapy--and-cell-therapy-defined. Accessed August 14, 2015.

2. Murugan V. Embryonic stem cell research: a decade of debate from Bush to Obama. Yale J Biol Med. 2009;82(3):101-103.

3. Lawrence, DJ. The four principles of biomedical ethics: a foundation for current bioethical debate. J Chiropr Humanit. 2007;(14):34-40.

4. Sabbatani S. The infectious diseases experiments conducted on human guinea pigs by Nazis in concentration camp. Infez Med. 2013;21(2):151-166.

5. Vargesson N. Thalidomide-induced teratogenesis: History and mechanisms. Birth Defects Res C Embryo Today. 2015;105(2):140-56.

6. Sackett DL, Rosenberg W, Gray JA, Haynes RB, Richardson, WS. Evidence based medicine: what it is and what it isn't. British Med J. 1996;312(7023):71-72.

7. Melnyk BM, Fineout-Overholt E, Stillwell SB, Williamson KM. Evidence-based practice: step by step: the seven steps of evidence-based practice. $A J N$. 2010;110(1):51-53.

8. Cohen AM, Stavri PZ, Hersh WR. A categorization and analysis of the criticisms of evidence-based medicine. Intl J Med Informatics. 2004; 73(1):35-43.

9. Klees JE, Joines R. Occupational health issues in the pharmaceutical research and development process. Occup Med. 1996;12(1):5-27.

10. Lipsky MS, Sharp LK. From idea to market: the drug approval process. J Am Board Fam Pract. 2001;14(5):362-367.

11. Huang H, Xi H, Chen L, Zhang F, Liu Y. Long-term outcome of olfactory ensheathing cell therapy for patients with complete chronic spinal cord injury. Cell Transplant. 2012;21(Suppl 1):S23-S31.

12. Saberi H, Moshayedi P, Aghayan HR et al. Treatment of chronic thoracic spinal cord injury patients with autologous Schwann cell transplantation: an interim report on safety considerations and possible outcomes. Neurosci Lett. 2008;443(1):46-50.

13. Moviglia GA, Varela G, Brizuela JA, et al. Case report on the clinical results of a combined cellular therapy for chronic spinal cord injured patients. Spinal Cord. 2009;47(6):499-503.

14. Sharma A, Sane H, Gokulchandran N et al. Role of autologous bone marrow mononuclear cells in chronic cervical spinal cord injury-a long term follow up study. J Neurol Disord. 2013;1:138.

15. Sharma A, Gokulchandran N, Sane H et al. Detailed analysis of the clinical effects of cell therapy for thoracolumbar spinal cord injury: an original study. J Neurorest. 2013;1:13-22.

16. Tabakow P, Jarmundowicz W, Czapiga B et al. Transplantation of autologous olfactory ensheathing cells in complete human spinal cord injury. Cell transplant. 2013;22(9):1591-1612.

17. Sharma A, Sane H, Gokulchandran N et al. Autologous bone marrow mononuclear cells intrathecal transplantation in chronic stroke. Stroke Res Treat. 2014;2014:234095.

18. Li ZM, Zhang ZT, Guo CJ, Geng FY, Qiang F, Wang LX. Autologous bone marrow mononuclear cell implantation for intracerebral hemorrhage-a prospective clinical observation. Clin Neurol Neurosurg. 2013;115(1):72-76.

19. oxforddictionaries.com [Homepage on the Internet], Oxford Dictionaries. Available from: http://www.oxforddictionaries.com/definition/ english/dementia. Accessed: August 14,2015. 
20. Nabar NR, Yuan F, Lin X, et al. Cell therapy: a safe and efficacious therapeutic treatment for Alzheimer's disease in APP+PS1 mice. PLoS One. 2012;7(12):e49468.

21. Blurton-Jones M, Kitazawa M, Martinez-Coria H, et al. Neural stem cells improve cognition via BDNF in a transgenic model of Alzheimer disease. Proc Natl Acad Sci U S A. 2009;106(32):13594-13599.

22. Gorba T, Harper S, Mee PJ. Prospects for neural stem cell therapy of Alzheimer disease. J Stem Cells Regen Med. 2011:337-348.

23. Sharma A, Badhe P, Gokulchandran N et al. Autologous Bone Marrow Derived Mononuclear Cell Therapy for Vascular Dementia. J Stem Cell Res Ther. 2011;2(129):2.

24. Martínez HR, Molina-Lopez JF, González-Garza MT, et al. Stem cell transplantation in amyotrophic lateral sclerosis patients: methodological approach, safety, and feasibility. Cell Transplant 2012;21(9):1899-1907.

25. Mazzini L, Mareschi K, Ferrero I, et al. Mesenchymal stromal cell transplantation in amyotrophic lateral sclerosis: a long-term safety study. Cytotherapy. 2012;14(1):56-60.

26. Mazzini L, Ferrero I, Luparello V et al. Mesenchymal stem cell transplantation in amyotrophic lateral sclerosis: A Phase I clinical trial. J Exp Neuro. 2010;223(1):229-237.

27. Karussis D, Karageorgiou C, Vaknin-Dembinsky A et al. Safety and immunological effects of mesenchymal stem cell transplantation in patients with multiple sclerosis and amyotrophic lateral sclerosis. Arch Neurol. 2010;67(10):1187-1194.

28. Martinez HR, Gonzalez-Garza MT, Moreno-Cuevas JE, Caro E, Gutierrez-Jimenez E, Segura JJ. Stem-cell transplantation into the frontal motor cortex in amyotrophic lateral sclerosis patients. Cytotherapy, 2009;11(1):26-34

29. Deda H, Inci MC, Kürekçi AE, et al. Treatment of amyotrophic lateral sclerosis patients by autologous bone marrow-derived hematopoietic stem cell transplantation: a 1-year follow-up. Cytotherapy. 2009;11(1):18-25.

30. Blanquer M, Moraleda JM, Iniesta F, et al. Neurotrophic bone marrow cellular nests prevent spinal motoneuron degeneration in amyotrophic lateral sclerosis patients: a pilot safety study. Stem Cells. 2012;30(6):1277-1285.

31. Blanquer M, Pérez EM, Iniesta F, et al. Bone marrow stem cell transplantation in amyotrophic lateral sclerosis: technical aspects and preliminary results from a clinical trial. Methods Find Exp Clin Pharmacol. 2010;32:31-37.

32. Prabhakar S, Marwaha N, Lal V, Sharma RR, Rajan R, Khandelwal N. Autologous bone marrow-derived stem cells in amyotrophic lateral sclerosis: a pilot study. Neurol India. 2012;60(5):465.

33. Sharma AK, Sane HM, Paranjape AA, et al. The effect of autologous bone marrow mononuclear cell transplantation on the survival duration in Amyotrophic Lateral Sclerosis-a retrospective controlled study. Am J Stem Cells. March 15 2015;4(1):50-65.

34. Huang H, Chen L, Xi H, et al. Fetal olfactory ensheathing cells transplantation in amyotrophic lateral sclerosis patients: a controlled pilot study. Clin Transplant. 2008;22(6):710-718.

35. Chen L, Huang H, Zhang J, et al. Short-term outcome of olfactory ensheathing cells transplantation for treatment of amyotrophic lateral sclerosis. Zhongguo Xiu Fu Chong JianWaiKeZaZhi [Chinese journal of reparative and reconstructive surgery]. 2007;21(9):961-966.

36. Chen L, Chen D, Xi H, et al. Olfactory ensheathing cell neurorestorotherapy for amyotrophic lateral sclerosis patients: benefits from multiple transplantations. Cell Transplant. 2012;21(Supp1 1):S65-S77.

37. Sharma A, Gokulchandran N, Sane H, et al. Autologous bone marrow mononuclear cell therapy for autism: an open label proof of concept study. Stem Cells Int. 2013;2013:623875.

38. Lv YT, Zhang Y, Liu M, et al. Transplantation of human cord blood mononuclear cells and umbilical cord-derived mesenchymal stem cells in autism. J Transl Med. 2013;27(11):196.

39. Chen L, Huang H, Xi H, et al. Intracranial transplant of olfactory ensheathing cells in children and adolescents with cerebral palsy: a randomized controlled clinical trial. Cell Transplant. 2010;19(2):185-191.
40. Chernykh ER, Kafanova MY, Shevela EY, et al. Autologous M2-like macrophage applications in children with cerebral palsy. Cell Ther Transpl. 2011;3:12-14.

41. Sharma A, Sane H, Gokulchandran N, et al. A clinical study of autologous bone marrow mononuclear cells for cerebral palsy patients: a new frontier. Stem Cells Int. 2015;2015:905874.

42. World Medical Association. World Medical Association Declaration of Helsinki: ethical principles for medical research involving human subjects. JAMA: The journal of the American Medical Association. 2013;310(20):2191.

43. European medicine agency. Guidelines on compassionate use of medicinal products. Available from: http://www.ema.europa. eu/docs/en_GB/document_library/Regulatory_and_procedural_ guideline/2009/10/WC500004075.pdf. Accessed: February 14, 2015.

44. Gunter KC, Caplan AL, Mason C, et al. Cell therapy medical tourism: time for action. Cytotherapy. 2010;12(8):965-968.

45. Huang H, Raisman G, Masri WS, et al. International Association of Neurorestoratology. Beijing Declaration of International Association of Neurorestoratology (IANR). Cell Transpl. 2009; 18(4):487.

46. Horn SD, Gassaway J. Practice-based evidence study design for comparative effectiveness research. Med care. 2007;45(10): S50-S57.

47. Green LW. Making research relevant: if it is an evidence-based practice, where's the practice-based evidence? Family practice. 2008;25(Suppl 1): i20-i24.

48. McDonald PW, Viehbeck S. From Evidence-Based Practice Making to Practice-Based Evidence Making Creating Communities of Research and Practice. Health Promot Pract. 2007;8(2): $140-144$.

49. Timmermans S, Mauck A. The promises and pitfalls of evidence-based medicine. Health Affairs. 2005;24(1):18-28.

50. The United States of America, Department of Health and Human Services, Code of Federal Regulations, Food and Drug Administration, Part 1271: Regulations for Human cells, Tissues, and Cellular and Tissue based products. Available from: http://www.accessdata.fda.gov/scripts/ cdrh/cfdocs/cfcfr/cfrsearch.cfm?cfrpart=1271\&showfr=1. Accessed: February 14, 2015.

51. Regulations on review and authorization of biological products 2010.10, Korea Food and Drug Administration. Available from: https://www.google. $\mathrm{com} / \mathrm{url}$ ? $\mathrm{sa}=\mathrm{t} \& \mathrm{rct}=\mathrm{j} \& \mathrm{q}=\& \mathrm{esrc}=\mathrm{s} \&$ source=web $\& \mathrm{~cd}=1 \& \mathrm{cad}=\mathrm{rja} \& u a c t=8$ \&ved=0CB4QFjAAahUKEwjYIN2itabHAhWVj44KHTnDBNE\&url= http $\% 3 \mathrm{~A} \% 2 \mathrm{~F} \% 2 \mathrm{Fwww}$.mfds.go.kr $\% 2 \mathrm{Fjsp} \% 2 \mathrm{Fcommon} \% 2 \mathrm{Fdownfile.}$

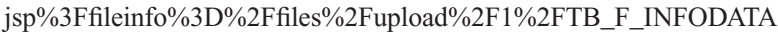
\%2F9218\%2F71d5a5a567f74eaa4586e4b8144a5824.pdf\&ei=W73MV Zj7BZWfugS5hpOIDQ\&usg=AFQjCNHZ4zFWcRlH0IV-mxSUJtnY1 Er35Q\&sig2=1jJTSpxuqquzKdFv539xNA\&bvm=bv.99804247,d.c2E. Accessed August 10, 2015.

52. Amendment of the pharmaceuticals affairs law. Available from: http:// www.mhlw.go.jp/english/policy/health-medical/pharmaceuticals/ dl/150407-01.pdf. Accessed: August 10, 2015.

53. Cyranoski D. Japan to offer fast-track approval path for stem cell therapies. Nature med. 2013;19(5):510.

54. Institutional framework for promoting implementation of regenerative medicine, Ministry of Health and Welfare Japan. Available from: http://www.mhlw.go.jp/english/policy/health-medical/medical-care/ dl/150407-01.pdf. Accessed: August 10, 2015.

55. Santos MJ, Ventura-Juncá P. Bioethical aspects of basic research and medical applications of human stem cells. Biol Res. 2012;45(3): $317-326$.

56. Signing of Stem Cell Executive Order and Scientific Integrity Presidential Memorandum Washington,DC, March 9, 2009 [press release]; Available from: https://www.whitehouse.gov/the-press-office/remarkspresident-prepared-delivery-signing-stem-cell-executive-order-andscientifi. Accessed August 10, 2015. 
Journal of Neurorestoratology

\section{Dovepress}

\section{Publish your work in this journal}

The Journal of Neurorestoratology is an international, peer-reviewed, open access online journal publishing original research and review articles on the subject of Neurorestoratology. To provide complete coverage of this revolutionary field the Journal of Neurorestoratology will

clinical achievements. The manuscript management system is completely online and includes a very quick and fair peer-review system, which is all easy to use. Visit http://www.dovepress.com/testimonials.php to read real quotes from published authors.

report on relevant experimental research, technological advances, and

Submit your manuscript here: http://www.dovepress.com/journal-of-neurorestoratology-journal 